American Journal of Animal and Veterinary Sciences 7 (2): 61-66, 2012

ISSN 1557-4555

(C) 2012 Science Publications

\title{
Mixed Species Grazing of Cattle and Goats on Gastrointestinal Infections of Haemonchus Contortus
}

\author{
${ }^{1}$ Renita Marshall, ${ }^{1}$ Sebhatu Gebrelul, ${ }^{1}$ Lisa Gray and ${ }^{2}$ Yemane Ghebreiyessus \\ ${ }^{1}$ Department of Animal Sciences, \\ Southern University Agricultural Research and Extension Center, \\ LA 70813, Baton Rouge, United States \\ ${ }^{2}$ Department of Urban Forestry, \\ Southern University and A and M College, LA 70813, Baton Rouge, United States
}

\begin{abstract}
At the present time, the meat of goat is the fastest growing class of livestock in the U.S.A. Due to the sub-tropical climate in the South Eastern region of the US, internal parasites pose a major constraint to the industry. The blood-feeding nematode, Haemonchus contortus results in production losses and even death in untreated animals. The control of $H$. contortus calls for the use of a combination of different control methods/strategies. An experiment was conducted over three successive years (2008, 2009 and 2010) to evaluate the effects of mixed species grazing on fecal egg counts (FEC in epg), FAMACHA ${ }^{\odot}$ scores (FS) and Packed Cell Volume (\% PCV) in goats. In a $2 \times 2$ factorial, 50 Spanish does and 14 Brangus cows were randomly assigned to continuous or rotational grazing systems. Goats were allowed to graze alone or mixed with cattle. The rotational pastures were divided into four paddocks and each paddock was grazed for $7 \mathrm{~d}$ and allowed to rest for $21 \mathrm{~d}$. Every $28 \mathrm{~d}$ Body Weight $(\mathrm{BW})$, body condition scores $(\mathrm{BCS} ; 1=$ thin and $5=$ fat $)$, FS $(1=$ red and $5=$ white $)$, blood and feces were collected. Fecal and blood samples were analyzed in the lab for FEC and \%PCV. Data was statistically analyzed using SAS's MIXED and correlation coefficients were determined among the measurements. Overall means for PCV, FEC, BCS and FS were 27.4\%, 613 epg, 2.3 and 2.5, respectively. PCV was negatively correlated to FS $(r=-0.35, \mathrm{p}<0.001)$ and FEC $(\mathrm{r}=-0.16, \mathrm{p}<0.005)$. BCS was negatively correlated to FS $(r=-0.59, \mathrm{p}<0.001)$ and FEC $(r=-0.17, p<0.005)$, while FS and FEC were positive $(r=0.20, p<0.005)$. Except for the effect of month $(\mathrm{p}<0.05)$, no differences due to the main effects were observed and interaction effects were significant at only $\mathrm{p}<0.10$. Goats grazing alone in continuous pastures had a higher PCV and FS scores (28.6\% and 2.7, respectively) than goats in mixed rotational pastures (25\% and 2.2). The percentages of does in mixed pastures falling in FS-1, FS-2 and FS-3 categories were higher (5.2 Vs $8.9 \%, 17.0 \mathrm{Vs} 22.7 \%$ and $15.7 \mathrm{Vs} 19.6 \%$, respectively) than does grazing alone. Overall, mixed grazing of pastures with cattle and goats reduced FEC in goats therefore decreasing FAMACHA scores that resulted in increased PCV and BCS values. The present data suggest alternative approaches for suppression of parasite loads include some management practices such as pasture rotation, mixed livestock species grazing and selective deworming.
\end{abstract}

Key words: Gastrointestinal nematodes, goats, Haemoncus contortus, fecal egg count, mixed grazing

\section{INTRODUCTION}

A major factor that negatively affects ruminant production worldwide is the infection with gastrointestinal nematodes. Economic evaluations have shown that major losses due to parasitism have been associated with animal production rather than mortality (McLeod, 1995; Perry and Randolph, 1999); therefore, parasitism by gastrointestinal nematodes is usually categorized as a production disease. Because of warm,

Corresponding Author: Renita Marshall, Department of Animal Sciences Southern University Agricultural Research and Extension Center, LA 70813, Baton Rouge, United States humid conditions during summer months, Gastrointestinal Nematodes (GIN) are the greatest health and production challenge for goats in southeastern states year round (Kaplan et al., 2004). Of the GINs, Haemonchus contortus is the most detrimental because of substantial economic losses. Haemonchus contortus or "The Barber Pole" worm thrives in warm, humid climates and is a voracious blood feeder that can cause anemia and death to the animal if left untreated. Haemonchus contortus or the 
"Barber Pole Worm" is considered to be the most important pathogen of goats and cattle in the tropical and subtropical environments. Haemonchus contortus has a short life cycle of less than three weeks. With favorable conditions, the eggs hatch and larvae develop to infective 3rd stage larvae in soil and manure. Worms mate in the host and females lay eggs that pass out in the feces. The eggs hatch and develop to infective larvae while remaining in the feces. The infective larvae then move out of the feces onto the surrounding forage where they can be consumed during grazing, thus completes the cycle. Upon digestion and completion of the life cycle, $H$. contortus is a highly pathogenic, blood sucking nematode causing clinical signs of anemia, edema (bottle-jaw), diarrhea and death. When clinical signs are present, $H$. contortus infection is commonly called haemonchosis, which results in pallor of the mucous membranes and skin (Bowman, 2003). Haemonchus contortus causes dramatic economic loss. This loss is due to decreased production, cost of prevention and treatment and ultimately death of infected animals. Haemonchosis is generally observed with a Fecal Egg Count (FEC) of 10,000 Eggs Per Gram (EPG) or higher.

Drug (anthelmintic) therapy has been used almost exclusively over the past few decades to control infections from $H$. contortus. The control of $H$. contortus involves the use of anthelmintics, which are used prohylactically rather than therapeutically. Resistance to anthelmintic treatment is the major concern in controlling parasitism in goat and possibly in cattle. Although nematode control strategies such as the use of anthelmintic drugs (benzimidazoles, imidazothiazoles and macrocyclic lactones) are in use, the problem has not been satisfactorily solved and, in some regions, it has even worsened due to the mismanagement of the drugs. Due to overuse of anthelmintics, $H$. contortus has adapted to the mechanism of action and resistance has become an issue. Anthelmintic resistant $H$. contortus is now an issue in Louisiana, the United States and globally. This widespread occurrence of anthelmintic resistance has made alternative control methods a necessity and has caused any new class of anthelmintics to be dealt with in such a way to preserve its efficacy. Due to this resistance reliance on anthelmintics is nearly impossible. The inevitable outcome of anthelmintic resistance is the need to implement strategies to delay the onset and severity of the problem. The control of $H$. contortus calls for the use of a combination of different control methods/strategies. Alternative control methods are needed, one of which is mixed-grazing. Parasites are generally species-specific; that is, cattle parasites affect cattle and not goats, while goat parasites affect goats but not cattle. The cattle may ingest the goat worm larvae, however and reduce the parasitic infestation of goats.
The current recommendation is to deworm only those individuals that need it. The most successful tool to access which animals need deworming due to $H$. contortus, is the FAMACHA $^{\odot}$ system. The FAMACHA $^{\odot}$ system assesses an animal's level of anemia by the color of the inside lower eyelid conjunctiva. This is used only for animals infected with $H$. contortus since it is a primary blood-sucker. It has been shown to be an effective way of determining which animals need deworming for haemonchosis (Wyk and Bath, 2002; Vatta et al., 2002; Kaplan et al., 2004). Our experience using the FAMACHA ${ }^{\circledR}$ method of estimating parasitism showed that mixed grazing by cattle and goats did not increase the prevalence or intensity of parasites and that there is no danger of inter-specific transfer.

An integrated control approach would use some combination of all the methods described above. In addition, some management practices such as pasture rotation and mixed livestock species grazing may also be useful.

Worm burdens may be reduced by treating only goats and cattle that are positive for worms in a limited rotational anthelmintic program. With the advent of widespread anthelmintic resistance, this method could be used to achieve successful control of $H$. contortus in Louisiana.

\section{MATERIALS AND METHODS}

The effects of mixed species grazing regime on $H$. contortus infections in goats was studied between 2008 and 2010. The experiment described here was conducted as part of a system-based study examining the effects of mixed species grazing systems and forage quality on the reproduction, growth and carcass traits of cattle and goats.

Experimental site, design and plot management: The experiment was conducted at the Southern University agricultural research and extension center experiment station in Baton Rouge, LA. The soil is silt loam soil, poorly drained and slowly permeable, with almost zero slopes. The plots comprised of 'improved' pastures and consisting mostly of perennial ryegrass, bermuda grass, alecia grass and tall fescue as permanent pastures.

In a $2 \times 2$ factorial arrangement, with two types of grazing (continuous Vs rotational) and two mixed animal grazing schemes (goats alone Vs goat mixed with cattle), 50 Spanish does and 14 Brangus cows were randomly assigned to grazing treatments presented in (Table 1). 
American J. Animal \& Vet. Sci., 7 (2): 61-66, 2012

Table 1: Treatment assignments

\begin{tabular}{|c|c|c|}
\hline \multirow[b]{2}{*}{ Treatment } & \multicolumn{2}{|l|}{ Livestock species } \\
\hline & $\begin{array}{l}\text { Cattle and goats together } \\
\text { (Mixed grazing) }\end{array}$ & Goats alone \\
\hline \multirow[t]{2}{*}{ Continuous grazing } & $\begin{array}{l}7 \text { cattle } \\
10 \text { goats }\end{array}$ & 15 goats \\
\hline & 8 hectares & 2 hectares \\
\hline \multirow[t]{2}{*}{ Rotational grazing } & $\begin{array}{l}7 \text { cattle } \\
10 \text { goats }\end{array}$ & 15 goats \\
\hline & 8 hectares & 2 hectares \\
\hline
\end{tabular}

A total of 20 ha were divided into two- 2 ha and two-8 ha Bermuda-grass (Cynodon dactylon) pastures. The initial stocking rate was based approximately upon 0.8 ha per cow and 0.2 ha per doe. The pastures were divided using a woven-wire fence. Several strands of electrical wire were applied to both sides of the wovenwire fence to keep out predators. The rotational grazing pastures were subdivided into four grazing paddocks using electric fencing. Fourteen Brangus beef cows and 50 Spanish does were randomly assigned to one of the four treatments (Table 1).

The grazing season was from March to September of each year for three years. During September and early October of each year, cattle and goats were confined to a small area of each pasture. The remaining area was lightly disked and overseeded with ryegrass and selected clovers for fall and winter grazing. Grazing resumed when the ryegrass was approximately $20 \mathrm{~cm}$ high.

Animals: Fourteen Brangus cows and fifty does were assigned to either continuous or rotational grazing with or without goats/cattle in the pastures. The animals were fed hay and supplements until the ryegrass was ready to be grazed. Animals had free access to water, salt and mineral mix at all times. Experimental animals were provided with supplemental feed in times of unexpected drought.

Bulls were placed in the treatment pastures during a 60-day breeding season (from May 1 to June 30 each year). The bulls rotated to a different pasture each week during the breeding season to remove the effects the sires might have on treatments. Calves were removed from the cows when they reached 210 days of age and placed on a different pasture until they reached an average weight of about $365 \mathrm{~kg}$. Heifers were used as herd replacements.

The breeding season for goats was restricted to September through early October to coincide with the ryegrass over-seeding of the pastures. During this time, does were confined in pens at the beef barn for pen breeding. Four Boer bucks were used for breeding and bucks rotated across the pens to neutralize sire effects that may influence performance. Standard animal husbandry practices (identification, vaccination, disbudding, castrating) were performed before kids were weaned. Kids were weaned at approximately three months of age. At weaning, kids were placed on pastures during the day and penned in the beef barn at night for 4-6 weeks. They were then moved to new pastures until they reached a weight range of $30-35 \mathrm{~kg}$.

Parasite monitoring: Every 28 days from March to September of each year, Body Weights (BW), Body Condition Scores (BCS; $1=$ thin and $5=$ fat), FAMACHA $^{\odot}$ scores $(\mathrm{FS} ; 1=$ red and $5=$ white), blood and feces were collected from each doe in the experiment. FAMACHA ${ }^{\odot}$ scores of goats were determined by observing the color of the mucous membranes of the lower eyelid. FAMACHA ${ }^{\oplus}$ has 5 levels, 1 (red, non-anemic) to 5 (white, severely anemic). All goats were female to remove any gender effects on parasitism (Shaw et al., 1995). Anthelmentic treatment of the goats was undertaken at intervals of 28 days. Goats with FAMACHA ${ }^{\odot}$ scores of 3 or higher were chosen to be dewormed. Goats on each plot were treated with Ivermectin and then again 28 days later if needed based upon fecal egg counts and FAMACHA ${ }^{\odot}$ scores. Fecal egg counts were measured in goats prior to each anthelmentic treatment every 28 days.

Sample and data collection and processing: Fecal and blood samples from each grazing regiment were analyzed to determine fecal egg counts per gram of sample (FEC) and Packed Cell Volume (PCV) percentages. Collected feces were evaluated to determine the number of parasite eggs excreted per gram of feces (epg). Fecal samples were transported and stored at $4{ }^{\circ} \mathrm{C}$, prior to processing within a week of collection. Fecal samples were homogenized to uniformly distribute the eggs throughout the feces prior to FEC determination using the Modified McMaster Test with one egg representing 50 eggs per gram (epg) of fresh feces. Fecal Egg Counts (FEC) were determined from feces collected, at the same time on each collection day, immediately prior to treatment with anthelmintics, directly from the rectum of each doe. Two grams of feces was placed into a $50 \mathrm{~mL}$ centrifuge tube and filled to $30 \mathrm{~mL}$ with salt solution. Samples were allowed to soak for a few minutes broken up (fecal pellets) and then mixed. With the use of a pipet, both chambers of the slide were filled. All eggs inside of the grid area were counted using 10X objectives. Only trichostrongyle eggs were counted. Total egg count (both chambers) X 50 equaled FEC (eggs per gram). 
Blood was collected from the jugular vein with the use of the vacutainer system with 21 gauge needle and a non-additive (red top) blood collection tube. The collected blood was analyzed in the lab for PCV determination. PCV is that percentage of blood that is red blood cells. The normal PCV percentage for goats is approximately 30\%. Twenty percent and lower indicates a signs of anemia.

Data analysis: Data was analyzed using SAS's MIXED and GLM procedures and regression and correlation analysis. Dependent variables included, Fecal Egg Counts (FEC) and Packed Cell Volume (PCV), Body Weights (BW), FAMACHA ${ }^{\odot}$ scores and Body Condition Scores (BCS). The main effects in the MIXED model, included grazing type (continuous vs. rotation) treatments and specie (goats alone or mixed with cattle) and interactions. Attempts were made to remove (adjust) random year fluctuations statistically. Contrast statements of interest were included to test various hypotheses. These included cattle grazing with goats Vs cattle grazing alone, goats grazing with cattle Vs goat grazing alone.

The general model is:

$Y_{i j k l m}=\mu+G_{i}+M_{j}+A_{k}+G_{i j}+R_{l}+\varepsilon_{i j k l m}$

Where:

$\mathrm{Y}_{\mathrm{ijklm}}=$ The dependent variable $(\mathrm{BW}, \mathrm{FS}, \mathrm{BCS}, \mathrm{PCV}$ and FEC)

$\mu \quad=$ The overall (constant) mean

$\mathrm{G}_{\mathrm{i}} \quad=$ The fixed effect of the $\mathrm{i}^{\mathrm{th}}$ grazing type, $\mathrm{i}=1,2$

$\mathrm{M}_{\mathrm{j}} \quad=$ The fixed effect of the $\mathrm{j}^{\text {th }}$ specie type grazing, $\mathrm{j}=1,2$

$\mathrm{A}_{\mathrm{k}} \quad=$ Random animal (goat or cow) effect

$\mathrm{GM}_{\mathrm{ij}}=$ The interactions of $\mathrm{G}$ and $\mathrm{M}$

$\mathrm{R}_{\mathrm{l}}=$ The random effect of the $\mathrm{k}^{\mathrm{th}}$ month effect

$\varepsilon_{\mathrm{ijklm}}=$ The uncontrollable variation, assumed to be normally and independently (NID) distributed, with $\mu=0$ and $\sigma=1$

Correlation and chi-square analysis were also used to determine relationships and percentages of the various non-parametric parameters measured in this project.

\section{RESULTS}

Partial correlations coefficients among PCV, BW, BCS, FS and FEC are given in (Table 2). PCV was positively $(\mathrm{p}<0.05)$ correlated with BCS and negatively correlated with FS $(\mathrm{p}<0.001)$ and FEC $(\mathrm{p}<0.01)$. BW was correlated $(\mathrm{p}<0.10)$ with BCS only. BCS was negatively $(\mathrm{p}<0.001)$ correlated with FS and FEC $(p<0.01$, while the latter two were positively $(p<) 0.10)$ correlated with each other.

Least square means of BW, PCV, BCS, FS and FEC classified by selective main and interactions effects are presented in (Table 3). Except for FEC that approached significance at $\mathrm{P}<0.10$, there was no differences in BW, PCV, BCS, FS and FEC due to goats grazing alone or mixed in cattle. The effect of month was significant $(\mathrm{p}<0.05)$ in the entire variable that we measured. PCV values decreased from $33.5 \%$ in April to 28.4 and $23.8 \%$ in August and September, respectively. BCS were higher in March and April (2.5), intermediate in May, June and July (2.3) and lower in August and September. FS ranged from 2.42.5 between March and June and between 2.7-2.9 between July and September. The highest $(p<0.05)$ FEC counts were observed in September. Goats in mixed rotational grazing had lower $(\mathrm{p}<0.05) \mathrm{PCV}$ percentages and FS scores than goats grazing alone in continuous grazing (23.7 Vs $28.6 \%$ and 2.2 Vs 2.7 , respectively) pastures. Although the significance level approached only $10 \%$, goat in mixed rotational pastures had lower FEC than the other groups.

Figure 1 represents the percentages of does falling in FAMACHA ${ }^{\circledR}$ Scores 1 through 4 . The percentages of does in mixed grazing falling in FS-1 through 3 were significantly $(\mathrm{p}<0.05)$ higher that does grazing alone. The percentage differences in FS-1, FS-2 and FS-3 were $3.7,5.7$ and 3.9 , respectively.

Table 2: Partial correlation coefficients of BW, BCS, FS and FEC

\begin{tabular}{lllll}
\multicolumn{5}{c}{ from the Error SSCP matrix } \\
\hline & BW & BCS & FS & FEC \\
\hline PCV & 0.06 & $0.25^{* * *}$ & $-0.35^{* * *}$ & $-0.16^{* *}$ \\
WT & & $0.10^{*}$ & -0.04 & 0.01 \\
BCS & & & $-0.59^{* * *}$ & $-0.17^{* *}$ \\
FS & & & $0.19^{* *}$ \\
\hline
\end{tabular}

Table 3: Least square means* of BW, PCV, BC, FS and FEC due to species, months and species grazing interaction

\begin{tabular}{lllllll}
\hline Species & $\mathrm{N}$ & BW & PCV & BCS & FS & FEC \\
\hline Alone & 80 & $42.5 \pm 2.1$ & $27.4 \pm 0.9$ & $2.2 \pm 0.04$ & $2.6 \pm 0.08$ & $799 \pm 188$ \\
Mixed & 180 & $43.7 \pm 2.1$ & $26.0 \pm 0.9$ & $2.3 \pm 0.04$ & $2.5 \pm 0.08$ & $582 \pm 187$ \\
Month & & & & & & \\
Mar & 40 & $57.2 \pm 4.2^{\mathrm{a}}$ & $10.3 \pm 1.9^{\mathrm{a}}$ & $2.5 \pm 0.1^{\mathrm{a}}$ & $2.4 \pm 0.2^{\mathrm{a}}$ & $60 \pm 379^{\mathrm{a}}$ \\
Apr & 40 & $47.5 \pm 4.2^{\mathrm{b}}$ & $33.5 \pm 1.9^{\mathrm{b}}$ & $2.5 \pm 0.1^{\mathrm{a}}$ & $2.4 \pm 0.2^{\mathrm{a}}$ & $181 \pm 379^{\mathrm{a}}$ \\
May & 80 & $42.2 \pm 3.0^{\mathrm{b}}$ & $30.7 \pm 1.3^{\mathrm{b}}$ & $2.3 \pm 0.1^{\mathrm{b}}$ & $2.4 \pm 0.1^{\mathrm{a}}$ & $260 \pm 268^{\mathrm{a}}$ \\
Jun & 80 & $41.6 \pm 3.0^{\mathrm{b}}$ & $29.4 \pm 1.3^{\mathrm{b}}$ & $2.2 \pm 0.1^{\mathrm{b}}$ & $2.5 \pm 0.1^{\mathrm{a}}$ & $438 \pm 270^{\mathrm{a}}$ \\
Jul & 40 & $39.1 \pm 4.2^{\mathrm{b}}$ & $30.9 \pm 1.9^{\mathrm{b}}$ & $2.3 \pm 0.1^{\mathrm{b}}$ & $2.7 \pm 0.2^{\mathrm{b}}$ & $572 \pm 379^{\mathrm{a}}$ \\
Aug & 40 & $37.1 \pm 4.2^{\mathrm{c}}$ & $28.4 \pm 1.9^{\mathrm{c}}$ & $2.0 \pm 0.1^{\mathrm{c}}$ & $2.7 \pm 0.2^{\mathrm{b}}$ & $656 \pm 379^{\mathrm{a}}$ \\
Sep & 40 & $6.9 \pm 4.2^{\mathrm{c}}$ & $23.8 \pm 1.9^{\mathrm{c}}$ & $2.2 \pm 0.1^{\mathrm{b}}$ & $2.9 \pm 0.2^{\mathrm{c}}$ & $2717 \pm 380^{\mathrm{b}}$ \\
Species & & & & & & \\
X Graze & & & & & & \\
Alone Cont & 90 & $46.1 \pm 2.9^{\mathrm{a}}$ & $28.6 \pm 1.3^{\mathrm{a}}$ & $2.2 \pm 0.1$ & $2.7 \pm 0.1^{\mathrm{a}}$ & $853 \pm 261$ \\
Alone Rotn & 90 & $38.9 \pm 2.9^{\mathrm{b}}$ & $26.3 \pm 1.3^{\mathrm{b}}$ & $2.2 \pm 0.1$ & $2.5 \pm 0.1^{\mathrm{b}}$ & $744 \pm 264$ \\
Mixed Cont & 90 & $43.7 \pm 2.9^{\mathrm{a}}$ & $27.0 \pm 1.3^{\mathrm{b}}$ & $2.4 \pm 0.1$ & $2.4 \pm 0.1^{\mathrm{b}}$ & $688 \pm 261$ \\
Mixed Rotn & 90 & $43.7 \pm 2.9^{\mathrm{a}}$ & $23.7 \pm 1.3^{\mathrm{c}}$ & $2.2 \pm 0.1$ & $2.2 \pm 0.1^{\mathrm{c}}$ & $474 \pm 264$ \\
Overall & & $42.8 \pm 1.4$ & $27.4 \pm 0.7$ & $2.3 \pm 0.1$ & $2.5 \pm 0.1$ & $613 \pm 130$
\end{tabular}

*; Means followed by different superscripts within each main effect are different at $\mathrm{p}<0.05$ 


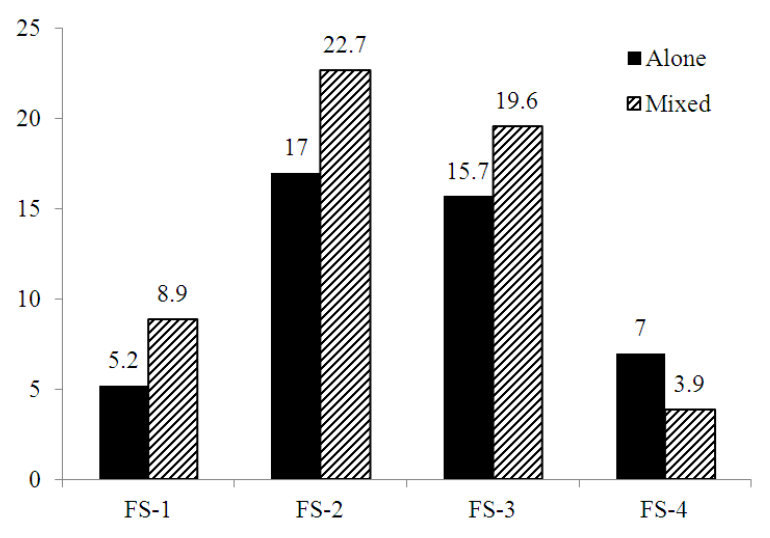

Fig. 1: Percentages of does falling in each Famacha ( category when grazing alone or mixed with cattle

\section{DISCUSSION}

Overall, grazing of pastures with cattle and goats reduced Fecal Egg Counts (FEC) in does compared with goat only systems. The lack of consistent relationship between does BCS, BW and FEC indicate that factors additional to internal parasites affected the live weight gain in goats in the different grazing systems. Factors affecting diet selection and intake by an animal on grazing pastures are complex in nature, due to interactions between dietary needs for nutrients (Hughes, 1993), sward structure (Black and Kenny, 1984), avoidance of feces (Hutchings et al., 2001) and the parasite intensities and parasite species present in the grazing host (Hutchings et al., 2000). For example, research has shown that reduced feed intake is related to the level of abomasal parasite infection (Coop et al., 1982).

Research findings on the impact of mixed grazing, with cattle and goats, on parasites and productivity of livestock are less clear (Barger, 1999). Bairden et al. (1995) reported that alternative grazing with cattle and sheep successfully reduced worm burdens over the first 2 years of a 4 year study. However, in years 3 and 4, this approach failed to control worm burdens but the study did not examine the impact on lamb worm burdens.

The positive correlation between PCV and BCS implies that goats that are in good condition can resist parasitic infestation because of higher WBC in their system. Improved PCV could be due to reduced number of blood feeding adult nematodes in the abomasum or improved nutrition allowing the animals to replace lost blood cells more quickly (Miller and Horohov, 2006). The negative correlated of PCV with FS is expected as PCV percentages increase FS values decrease (the lower FS values, the (better the animal is). This might suggest that using the FAMACHA chart (Vatta et al., 2002) would be a suitable approach to control nematode infections in goats in the southeast. The use of the FAMACHA $^{\odot}$ chart would be a suitable approach for hoppy or small limited resources farmers. FEC are expected to increase as animals are infected and PCV values are lower, hence the negative correlation.

The effect of month was significant $(p<0.05)$ in the entire variable that we measured. It is interestingly to note that the highest $(\mathrm{p}<0.05)$ FEC counts were observed in September. This is consistent with the findings of Eysker et al. (2005) that demonstrates that in the second half of August, or even earlier, $H$. Contortus can be programmed to inhibit development within a 4 week period between egg deposition and translation of larvae to pasture.

\section{CONCLUSION}

This study demonstrates that overall, mixed grazing of pastures with cattle and goats reduced fecal egg counts in goats therefore decreasing FAMACHA ${ }^{\odot}$ scores that resulted in increased Packed Cell Volumes (PCV) and Body Condition Score (BCS) values. These studies support the observation that mixed species grazing of cattle and goats on the same pastures proves to be beneficial in decreasing the quantity and effects of Haemonchus contortus infections of goats. Alternative control methods are needed, one of which is mixed-grazing. The Southern University Agricultural Research and Extension Center has been experimenting with mixed-species grazing systems for the last five years. We have learned a great deal and we understand what is needed to enhance our investigative tools and incorporate new approaches to make the system work more efficiently. Further studies are needed on how to enhance the utilization of available forages through intensive sequential grazing and mixing one or more livestock species.

\section{ACKNOWLEDGEMENT}

This study is part of a project titled "Effect of mixed species grazing systems and forage quality on the reproduction, growth and carcass traits of cattle and goats" which was funded by NIFA/USDA and implemented by Southern University Agricultural Research and Extension Center (SUAREC). We want to express our sincere appreciation to Dr. Veera Bachireddy, Mila Berhane, Roosevelt Payne and Eugene Runles for all their help in the preparation and analysis of this study. The support of the SUAREC Experiment Station in the establishment of the goat herd is also acknowledged. 


\section{REFERENCES}

Bairden, K., J. Armour and J.L. Duncan, 1995. A 4year study of the effectiveness of alternate grazing of cattle and sheep in the control of bovine parasitic gastro-enteritis. Vet. Parasitol., 60: 119132. DOI: $10.1016 / 0304-4017(94) 00750-7$

Barger, I.A., 1999. The role of epidemiological knowledge and grazing management for helminth control in small ruminants. Int. J. Parasitol., 29: 4147. PMID: 10048818

Black, J.L. and P.A. Kenny, 1984. Factors affecting diet selection by sheep. 2. Height and density of pasture. Aust. J. Agric. Res., 35: 565-578. DOI: 10.1071/AR9840565

Bowman, D.D., 2003. Georgis' Parasitology for Veterinarians. 8th Edn., Saunders, ISBN-10: 0721692834, pp: 432.

Coop, R.L., A.R. Sykes and K.W. Angus, 1982. The effect of three levels of intake of Ostertagia Circumcincta Larvae on growth rate, food intake and body composition of growing lambs. J. Agric. Sci., $\quad 98$ : 247-255. DOI: 10.1017/S0021859600041782

Eysker, M., N. Bakker, F.N.J. Kooyman, H.W. Ploeger, 2005. The possibilities and limitations of evasive grazing as a control measure for parasitic gastroenteritis in small ruminants in temperate climates. Veter. Parasitol., 129: 95-104. DOI: 10.1016/j.vetpar.2004.12.022

Hughes, R.N., 1993. Diet Selection: An Interdisciplinary Approach to Foraging Behaviour. 1st Edn., Blackwell Scientific Publications, Oxford, ISBN-10: 0632035595, pp: 221.

Hutchings, M.R., I.J. Gordon, E. Robertson, I. Kyriazakis and F. Jackson, 2000. Effects of parasitic status and level of feeding motivation on the diet selected by sheep grazing grass/clover swards. J. Agric. Sci., 135: 65-75. DOI: 10.1017/S002185969900790X
Hutchings, M.R., I.J. Gordon, I. Kyriazakis and F. Jackson, 2001. Sheep avoidance of faecescontaminated patches leads to a trade-off between intake rate of forage and parasitism in subsequent foraging decisions. Anim. Behav., 62: 955-964. DOI: 10.1006/anbe.2001.1837

Kaplan, R.M., J.M. Burke, T.H. Terrill, J.E. Miller and W.R. Getz et al., 2004. Validation of the FAMACHA eye color chart for detecting clinical anemia in sheep and goats on farms in the southern United States. Vet. Parasitol. 123: 105-120. PMID: 15265575

McLeod, R.S., 1995. Costs of major parasites to the Australian livestock industries. Int. J. Parasitol., 25: 1363-1367. DOI: 10.1016/0020-7519(95)00071-9

Miller, J.E. and D.W. Horov, 2006. Immunological aspects of nematode parasite control in sheep. J. Anim. Sci., 84: E124-E132. PMID: 16582083

Perry, B.D. and T.F. Randolph, 1999. Improving the assessment of the economic impact of parasitic diseases and of their control in production animals. Vet. Parasitol., 84: 145-168. PMID: 10456413

Shaw, K.L., J.V. Nolan, J.J. Lynch, O.R. Coverdale and H.S. Gill, 1995. Effects of weaning, supplementation and gender on acquired immunity to Haemonchus contortus in lambs. Intern. J. Parasitol., 25: 381-387. DOI: 10.1016/00207519(94)00098-9

Vatta, A.F., R.C. Krecek, B.A. Letty, M.J. Van Der Linde and R.J. Grimbeck et al., 2002. Incidence of Haemonchus spp. and effect on haematocrit and eye colour in goats farmed under resource-poor conditions in South Africa. Vet. Parasitol., 103: 119-131. PMID: 11751007

Wyk, J.A.V. and G.F. Bath, 2002. The FAMACHA system for managing haemonchosis in sheep and goats by clinically identifying individual animals for treatment. Vet. Res., 33: 509-529. PMID: 12387487 